\title{
The gas-dynamic antifriction coating of babbitt for bearings of the turbine rotor
}

\author{
Irina Tsareva ${ }^{1}$, Olga Berdnik ${ }^{1, *}$, Lyudmila Krivina ${ }^{1}$, and Yuri Levanov ${ }^{1}$ \\ ${ }^{1}$ Institute of Mechanical Engineering Problems of the Russian Academy of Sciences - Branch of FIC \\ IPF RAS, Nizhny Novgorod, Russia
}

\begin{abstract}
The application of the anti-friction coating of babbitt on the working surface of sliding bearings is an important technological procedure necessary both for their manufacture and for their repair. To extend the service life and restore the performance of bearings, the coating is preferably applied by gas-dynamic spraying, The coating formed by this method has a low porosity, high adhesion strength and low friction coefficient.
\end{abstract}

\section{Introduction}

The paper is devoted to the study of the babbitt coating deposited on bearings by gasdynamic high-speed spraying. In modern steam turbines, segment bearings are mainly used. The properties of the segments that make up the bearing affect its reliability and service life. In the process of manufacturing or repairing the segment, its surface is covered with a layer of babbitt ( $1.5 \mathrm{~mm}$ thick) by immersion or spraying. Babbitt serves as an antifriction coating for bearings, which is necessary when working in semi-dry friction. The service life of bearings depends largely on the thickness of the babbitt coating. When thinning the working layer to $0.8-0.9 \mathrm{~mm}$, a new layer of babbitt is applied to the segments.

\section{Objects of research and experimental technique}

The paper studies specimens cut from 20X13 steel, coated with babbitt using the gas dynamic spraying method. Babbitt coating formed from a powder mixture of grade B-83100-40 (B-83) with a composition according to GOST 1320-74: Sn - $83 \%$, Sb - $11 \%$, UK $-6 \%$. Babbitt is a tin-based alloy with a melting point of $300-440^{\circ} \mathrm{C}$. A characteristic feature of this alloy is that it is a plastic mass with uniformly distributed solid particles, which serve as support points for the necks of the shafts and are pressed deep into the soft base under an inhomogeneous load. In this case, the shaft pressure on the liner is evenly distributed over the entire sliding surface, which allows the bearing to withstand a large load.

The hardness of the babbitt is always less than the hardness of the material of the neck of the shaft, therefore, the abrasive wear of the surface of the babbitt bearing is greater.

\footnotetext{
* Corresponding author : berdnik80@mail.ru
} 
During engine operation, this fact causes an increase in the radial clearance in the bearings and the appearance of deaf metal knocks. Applying coating on the surface of the bearings or replacing the liners will help eliminate this defect. However, application of babbitt coating on bearings (fig. 1) is a complex technological procedure. Only strict observance of all requirements allows to receive bearings of high quality. The most optimal method for obtaining high-quality coating is the method of gas-dynamic spraying.
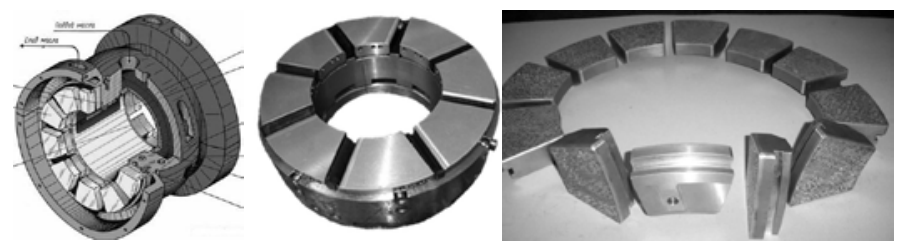

Fig. 1. The appearance of coated bearing.

Initially, preliminary preparation of the specimen surface is carried out, which consists in obtaining a uniform roughness using abrasive processing with corundum grade K-00-0416. Then, a multilayer coating is sprayed onto the prepared cylindrical specimens. The feed rate of powder materials during the coating is $0.5-0.6 \mathrm{~g} / \mathrm{s}$. The first stage is the coating of a copper sublayer (thickness 50 microns) from a powder mixture of grade SK20 (the distance between the nozzle and the sample surface is $10-20 \mathrm{~mm}$ ). Then a thin coating of tin powder mixture is applied to its surface. The thickness of the working coating babbitt is $\sim 1 \mathrm{~mm}$. After coating, the specimen is mechanically finished to smooth the surface roughness.

Optical and electron microscopy methods were used to study the microstructure of the cross section of the babbitt coating. The microhardness test was performed by Vickers hardness test at a load of $0.5 \mathrm{~N}$. Adhesion strength between the coating and the substrate was measured by indentation (at a load of $2 \mathrm{~N}$ ). The friction properties of the coating and the base material were studied using a laboratory friction unit [2].

\section{Results}

Babbitt (B-83 powder) is used for applying antifriction coatings on engine related parts, in particular, sliding bearings. The powder consists of large particles, the size of which is from 5 to 50 microns. (fig. 2 a). There are individual small particles with a diameter of $\sim 1$ microns and large conglomerates up to 80 - 100 microns. The particles of the powder mixture have a mainly elongated globular shape, which is due to the technological features of its manufacture (fig. 2 b) [2]. This mixture is made using modern technology of powder metallurgy. First, the components are ground to powder with further mixing in the required ratio (by weight. \% Babbitt alloy grade B-83). Then the resulting mixture is melted with periodic stirring to obtain an alloy with a crystallization temperature of $70{ }^{\circ} \mathrm{C}$ and a melting point above $300^{\circ} \mathrm{C}$.

X-ray diffraction analysis showed that the powder mixture has a phase composition: Sn $+-\mathrm{SbSn}+\mathrm{Cu}(\sim 6 \%)$. Antimony is the main phase and has a tetragonal type of crystal lattice. The intermetallic phase is formed during heat treatment, which is one of the stages of manufacturing the powder mixture. According to phase-rule diagram of the system «Sn-Sb», its volume fraction corresponds to $11 \%$ of the mass fraction of antimony (fig. 4) [3]. The resulting babbitt coating has a phase composition similar to the powder (fig. 3). It should be noted that the temperature of the particles in the high-speed flow does not exceed $200{ }^{\circ} \mathrm{C}$ during dynamic deposition, which explains the constancy of the phase composition. A change in the intensity of some Debye-Scherrer reflections of tin was found, which may be 
due to plastic deformation of the particles when they collide with the substrate and, as a consequence, a change in the shape of the grains in the coating. The appearance of the model specimen coated with babbitt and the structure of its cross-section are shown in fig. 5-7.

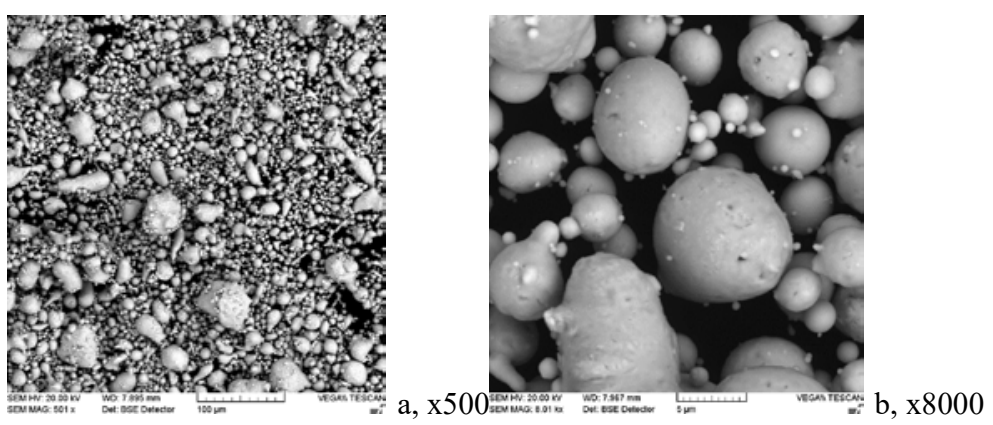

Fig. 2. Granular composition of the powder mixture of babbitt

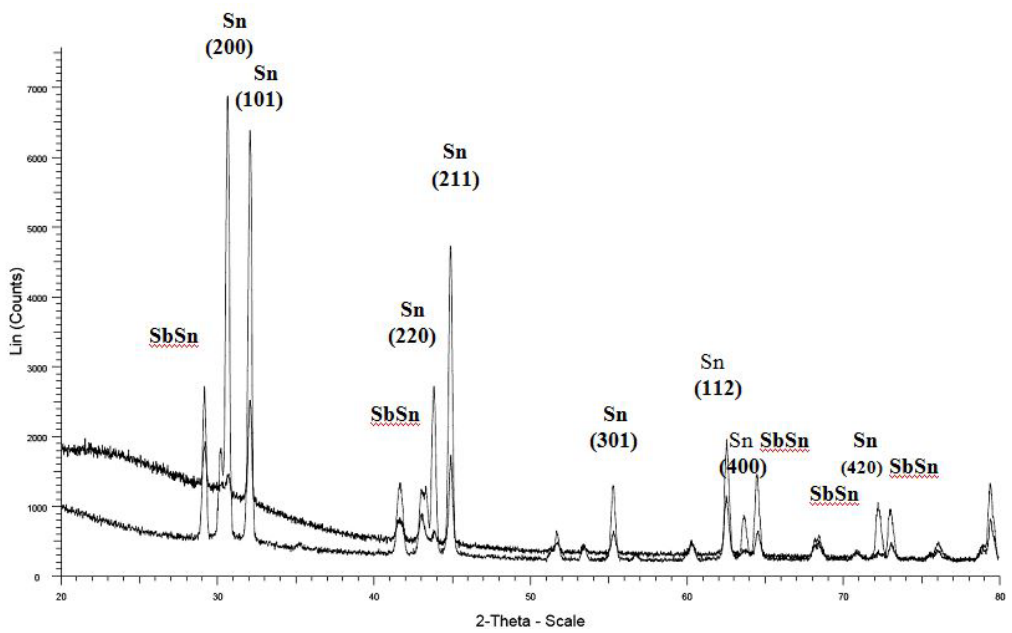

Fig. 3. X-ray diffractogram of the powder mixture of babbitt and the coating obtained from this powder mixture

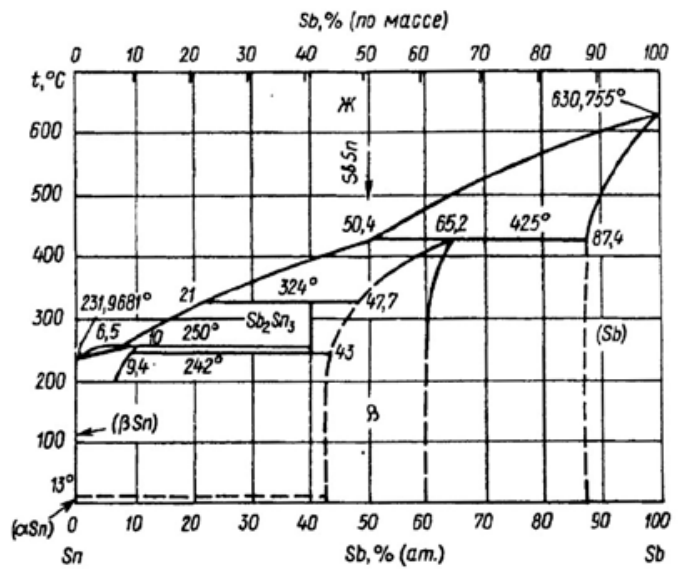

Fig. 4. Phase-rule diagram of the system «Sn-Sb» 
Studies of the cross-section of the coating using an optical microscope showed that the coating consists of three layers (fig. 6). The microstructure of the babbitt coating consists of a solid solution (dark base in fig. 6b), large cubic particles (SbSn) and small crystals (Cu6Sn5; Cu3Sn). It has also been found that the babbitt coating has a low porosity. The presence of open and surface porosity in the coating was not revealed. The average value of the total porosity $\mathrm{N} \sim 3 \%$, in areas with maximum pore accumulation- $\mathrm{N} \sim 5 \%$. The diameter of large pores is 27.5 microns, small-7 microns (fig. 7). The application of the technological approach of applying the copper sublayer provides a smooth change in hardness from the substrate to the coating, which has a positive effect on the stress distribution over the layers. During the test of adhesive strength of the interface "coatingsublayer" and "sublayer - substrate" by micro-indentation, no cracks, chips or flaking were found. This fact indicates a high adhesive strength between all layers of the coating. Friction tests showed that the friction coefficient of the base material is $\mathrm{f}=0.152$; and the friction coefficient of the babbitt coating is $f=0,098$. Thus, the coating of babbitt on the steel surface leads to a decrease in the coefficient of friction by $\sim 1.5$ times.

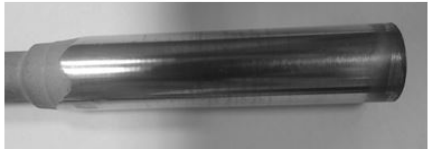

a

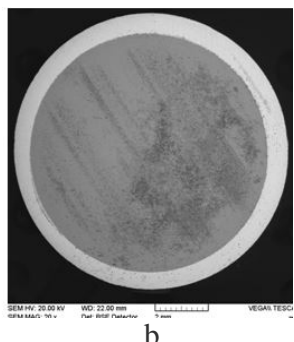

b

Fig. 5. Appearance of the specimen coated with babbit (a) ; transverse section (b), X200

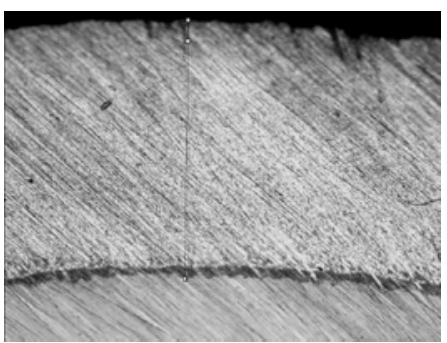

a, $\times 50$

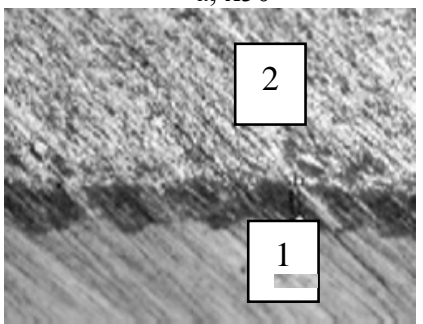

c, 100

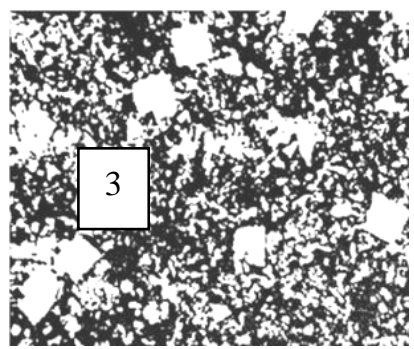

$\mathrm{b}, \mathrm{x} 100$

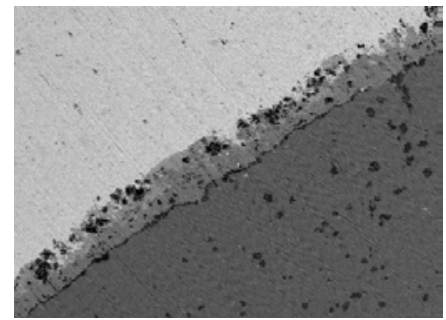

$\mathrm{d}, \mathrm{x} 50$

Fig. 6. Babbitt coating structure: 1,2-sublayers, 3-working layer

According to the molecular-deformation model of friction, the friction coefficient is the sum of the molecular and deformation components:

$$
f=f_{M}+f_{D}
$$


The first term arises due to intermolecular interactions in sufficiently close areas of solids, and the second term is associated with the deformation of a thin surface layer and its introduction into another material. In order to perform the approximate calculations for the case of a slip of a single spherical indenter in a plane (under conditions of unsaturated plastic contact), we can use the expression [4]:

$$
f=\frac{\tau_{c}}{H B}+\frac{0,31}{R} \sqrt{\frac{N}{H B}}
$$

where $\tau_{\mathrm{c}}$ - average shear stress, hardness of material, HB - the load on the indenter, $\mathrm{R}$ - is the radius of the ball indenter. By calculating, in accordance with (2), the deformation component of the friction coefficient $f_{D}$ and using the experimental value of the friction coefficient $\mathrm{f}$, we can determine the molecular component $\mathrm{fm}$, and from it the average stress per section of the surface layer. For steel surface shear stress $\tau_{\mathrm{c}}=45.2 \mathrm{~kg} / \mathrm{mm}^{2}$, and the surface of the babbitt - $\tau_{\mathrm{c}}=3.1 \mathrm{~kg} / \mathrm{mm}^{2}$. Thus, the application of babbitt coating on a steel part facilitates the shift of the surface layer during friction plowing, and babbitt coating acts as an antifriction coating.
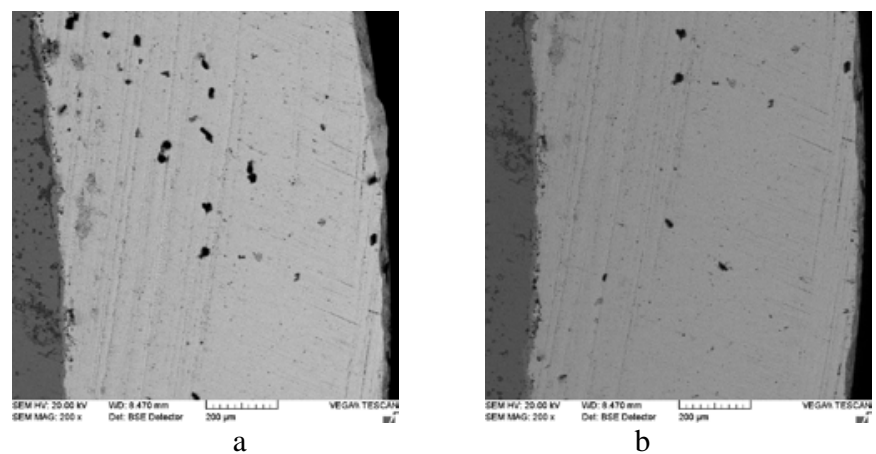

Fig. 7. Areas of babbitt coating with different porosity: a-maximum pore accumulation; b-average pore accumulation, X200

\section{Conclusion}

Spraying coating by gas-dynamic completely eliminates the possibility of cavities or solid inclusions, evenly distributing babbitt on the bearing surface. This leads to an improvement in the quality of babbitt layers

High adhesive strength, fairly low porosity, a reduced coefficient of friction by 1.5 times (compared with steel), facilitating shear of the surface layer of babbitt coating in contact with the shaft journal during operation, improves the reliability of the bearing and reduces the risk of accidental failure.

The method of gas-dynamic spraying allows to obtain better coatings of babbitt, it is economical and less labor-intensive in comparison with the known immersion method.

Work was performed within the given state task by the Institute of Applied Physics of the Russian Academy of Sciences for carrying out fundamental scientific research during 2013-2020 on a subject No. 0035-2014-0401 (No. of state registration 01201458049). 


\section{References}

1. V.E. Arkhipov, A.F. Landarski, G.V. Moskvitin, M.S. Pugachev Gas-dynamic spraying. Structure and properties of coatings. M.: Publishing house "Krasand" (2017)

2. https://findpatent.ru/patent/234/2343216.html

3. Phase-rule diagram of the double metal systems, ed. N.P.Lyakisheva, M.: Mashinostroenie (2000)

4. I.V. Kragelsky, N.M. Mikhin Friction units of the machines Directory. Moscow: Mashinostroenie (1984) 